\title{
Review
}

\section{Applied predictive analytics and developing analytical talent}

\author{
Applied predictive analytics: Principles and techniques for the \\ professional data analyst \\ Dean Abbott \\ John Wiley \& Sons, London, 2014; softback; £33.99; 456pp; \\ ISBN: 978-1118727966
}

\author{
Developing analytical talent: Becoming a data scientist \\ Vincent Granville \\ John Wiley \& Sons, London, 2014; softback; £26.99; 336pp; \\ ISBN: 978-1118810088
}

Journal of Direct, Data and Digital Marketing Practice (2014) 16, 66-67. doi:10.1057/dddmp.2014.39

\section{Rewarding, varied and meaningful career}

\section{Elegance must be replaced by simplicity}

\section{Use simple and straightforward techniques}

Having burrowed away, enthused and fascinated by the challenges of finding useful insights within datasets for more years than I ought to remember, it is somewhat disconcerting to find my profession the centre of so much current attention. It isn't news to me what a rewarding, varied and meaningful career this is - but now, others seem to be getting the message as the volume and pace of change becomes more visible to the public consciousness. Therefore, this review covers two books that are seeking to articulate both the complexity of the current situation and the toolset that is available to comprehend structure and meaning within what at first glance is a burgeoning cauldron of digits.

My own sense is that, to be worthy of the title 'scientist' (data or otherwise), what the individual needs to contribute is the identification of some semblance of order behind apparent chaos by visualizing abstractions that lie behind the confused initial and immediate impressions, bringing to the fore tell-tale fingerprints of a thought less seen. While in the academic world a scientist might be lauded for the sheer elegance and universality of their solution, this is insufficient within the pragmatic world of business and commerce. Elegance must be replaced by simplicity of communication and universality replaced by the ability to solve specific problems and drive change.

Measurement is an integral part of the scientific method and this leads to some bifurcation in attention. On the one hand, there is a fascination with how much bigger, smaller or faster measurements can be made and the principles of the underlying technology that facilitates this. On the other, is a fascination with the world that is described and quantified by the technology and can often benefit from a simple, straightforward approach within a new territory. I suspect the choice is something of a matter of taste and I am now firmly on the side of describing the world 
using techniques that are themselves as simple and straightforward as possible. This may well be reflected in my own response to the two books reviewed.

New and chaotic, or just a new name?

\section{Rigorous science or boundary stretching}

\section{Something to learn from both}

Both books cover the same material, based upon extensive experience, but with a distinctly different tone: for Granville, everything is new, chaotic, unstructured and different from what has been before; for Abbott, even predictive analytics is merely a name change forced upon the community by PR and marketing, and he sets the outline within a clear and practical problem-solving framework. For Granville, a data scientist is defined more by what they are not - they are not statisticians or analysts, they are trying out new techniques, and have a knowledge of the latest software and social media knowledge exchange. For Abbott, the drive is to identify how the tried-and-tested scheme of business and data understanding, exploration, insight and implementation is applied in the new environment in which we find ourselves.

For me, the biggest challenge of any problem-solving exercise, especially one dependent on data exploration, is to ensure that your conclusions are not a mere artefact of your method, but at the end of the process stand on their own merits. This leads to a preference for clear, conscious and methodical approaches that are mixed with a healthy dose of scepticism. Thus, I warmed to Abbott's approach and mean it as a compliment that the book is comprehensive, methodical, clearly written and appropriately 'dull'. For me, that is the heart of a rigorous scientific method that, as a result, uncovers robust, novel and innovative insights and solutions. On the other hand, I have to remember there are those who are more invigorated by Granville's more effusive, unstructured and cavalier approach. They can stretch techniques and technologies beyond failing point and so enable others to learn, too, about the nature of boundaries and regions of applicability.

It takes all sorts to extend the pool of talented data technicians, be they analysts, scientists, engineers, statisticians or geeks. Whatever you aspire to be, you may get time to read both books profitably. However, should you want to choose and want a sense of diving straight into the 'Wild West' of data science, choose Granville. If you want to spend some time honing your skills and sharpening your toolset, go for Abbott. 